\title{
LOIC WACQUANT: ENCARCERAMENTO EM MASSA COMO POLÍTICA SOCIAL NA CONTEMPORANEIDADE
}

\author{
LOIC WACQUANT: ENCARGADO EN MASA COMO POLÍTICA SOCIAL EN \\ LA CONTEMPORANEIDAD
}

\author{
LOIC WACQUANT: MASS INCARCERATION AS A SOCIAL POLICY IN \\ CONTEMPORANEITY
}

\author{
Renata Almeida DANIN ${ }^{1}$
}

RESUMO: No decorrer das quatro últimas décadas, a América lançou-se numa experiência social e política sem precedentes. A substituição de um Estado de bem estar social por um Estado penal, indica que a criminalização da marginalidade e a contenção punitiva das categorias deserdadas confundem-se com a política social: os programas voltados para as populações vulneráveis foram sempre limitados e isolados do resto das atividades estatais. Dessa forma, a vocação disciplinar se afirma principalmente na direção das classes inferiores e das categorias étnicas dominadas. Veremos através deste artigo a conjuntura do aprisionamento afro-americano segundo Loic Wacquant.

PALAVRAS-CHAVE: Loic Wacquant. Gueto. Encarceramento em Massa. Estado Penal.

RESUMEN: En el transcurso de las cuatro últimas décadas, América se ha lanzado en una experiencia social y política sin precedentes. La sustitución de un Estado de bienestar social por un Estado penal, indica que la criminalización de la marginalidad y la contención punitiva de las categorías desheredadas se confunden con la política social: los programas dirigidos a las poblaciones vulnerables siempre han sido limitados y aislados del resto actividades estatales. De esta forma, la vocación disciplinaria se afirma principalmente en la dirección de las clases inferiores y de las categorías étnicas dominadas. Veremos atraves de este artículo la coyuntura del encarcelamiento afroamericano según Loic Wacquant.

PALABRAS CLAVE: Loic Wacquant. Gueto. Encarcelamiento en masa. Estado Penal.

ABSTRACT: Over the last four decades, America has embarked on an unprecedented social and political experience. The replacement of a state of social welfare by a criminal state indicates that the criminalization of marginality and punitive containment of disinherited categories are confused with social policy: programs aimed at vulnerable populations have always been limited and isolated from the rest of the activities. In this way, the disciplinary vocation is affirmed mainly in the direction of the inferior classes and of the dominated ethnic categories. We will see through this article the conjuncture of Afro-American imprisonment according to Loic Wacquant.

${ }^{1}$ Universidade Federal do Pará (Ufpa), Belém - PA - Brasil. Mestranda do Programa de Pós-Graduação em Segurança Pública. E-mail: renatadanin@gmail.com. 
KEYWORDS: Loic Wacquant. Ghetto. Mass Incarceration. Penalty State.

\section{Introdução}

Vários fatores devem ser considerados no que diz respeito à desigualdade racial e aprisionamento na América contemporânea. Desde 1989 e pela primeira vez na história da nação, afro-americanos são maioria nas prisões, e este número só aumenta a cada ano. Há quatro décadas, a composição de internos nas prisões americanas mudou, no meio do século $70 \%$ dos prisioneiros eram brancos, hoje em dia $70 \%$ são negros e latinos. Embora não tenham ocorrido mudanças nos padrões étnicos de atividade criminal durante o período.

A taxa de encarceramento de afro-americanos tem aumentado em níveis alarmantes comparados a outras sociedades, e é mais alto agora que a taxa total de encarcerados na antiga União Soviética ou na África do Sul no alto da luta contra o apartheid.

Em meados de 1999, quase 800.000 homens negros foram detidos em penitenciárias federais, prisões estaduais e cárceres. Um terço dos afro-americanos na casa dos 20 anos se encontra atrás das grades ou em liberdade condicional. E em antigas cidades industriais do norte, esta proporção chega a exceder muitas vezes os dois terços.

A taxa de negros comparada à taxa de brancos aprisionados tem crescido constantemente nas ultimas décadas. Isto eleva a desproporcionalidade racial e tem ligação direta com a política de guerra as drogas criada por Ronald Reagan e expandida posteriormente sob o governo de George Bush e Bill Clinton respectivamente. Em alguns estados, afro-americanos são aprisionados 10 vezes mais se comparados à taxa de americanos descendentes de europeus. No distrito de Columbia, por exemplo, negros são 35 vezes mais prováveis de estarem atrás das grades do que brancos.

A maioria dos analistas explica o súbito "enegrecimento" do sistema carcerário que inclui prisões, prisões estaduais, prisões federais e instalações privadas de detenção em termos de tendências no crime e seu tratamento judicial (prisão, acusação e sentença). Alguns consideraram variáveis não judiciais, como o tamanho da população negra, fatores econômicos (taxa de pobreza, desemprego, renda), o valor dos pagamentos de assistência social, o apoio ao fundamentalismo religioso e o partido político dominante. Mas esses fatores, tomados separadamente e em conjunto, simplesmente não podem explicar a magnitude, a rapidez e o momento da recente racialização da prisão dos EUA, especialmente 
porque as taxas de criminalidade foram estáveis e depois aumentaram em demasia ao longo do último quarto de século.

Esta política de encarceramento em massa tem como principais vítimas os jovens pobres e em sua maioria negros que são usuários de drogas ou praticam pequenos furtos. Ao contrário do que se é frequentemente noticiado na mídia, às prisões estão repletas não de criminosos violentos, mas sim de pequenos delinquentes e usuários de drogas.

O problema deste artigo concentra-se em relacionar a desigualdade racial e o encarceramento em massa nos Estados Unidos dentro da perspectiva de Loic Wacquant. O objetivo geral visa compreender como a questão racial e social está diretamente associada ao aprisionamento. O objetivo específico é identificar os fatores sociais, raciais e políticos que fomentam o encarceramento em massa e contribuem para a formação do atual Estado Penal estadunidense.

Nosso objeto de estudo é a política de Encarceramento em Massa e o Estado Penal na América contemporânea através da discussão racial. Trata-se de pesquisa bibliográfica e documental, realizada através de revisão bibliográfica das obras de Loic Wacquant. O trabalho analisa o Estado Penal e as medidas governamentais discriminatórias contra negros, latinos e pobres nos Estados Unidos da América e sua influência no Estado brasileiro.

\section{Estado Penal americano contemporâneo}

Ao sair do paradigma crime e punição e examinar o papel mais amplo do sistema penal como instrumento para gerenciar grupos despossuídos e desonrados. O desenvolvimento de uma visão sobre as formas de dominação etno-racial nos Estados Unidos e o incômodo aumento no encarceramento negro nas últimas quatro décadas resulta da obsolescência do gueto como um dispositivo para o controle de castas e a necessidade correlativa de um aparelho substituto para manter os afro-americanos (não qualificados) em uma posição subordinada e confinada fisicamente, socialmente e simbolicamente (WACQUANT, 2009).

O gueto e o sistema carcerário em expansão tornaram-se ligados em um único sistema que atrai grande número de homens negros jovens. Essa malha carcerária emergiu de dois conjuntos de mudanças convergentes: as forças econômicas e políticas arrebatadoras reestruturaram o "cinto preto" de meados do século para tornar o gueto mais como uma prisão. E a "sociedade do preso" quebrou de forma que torna a prisão mais como um gueto. A simbiose resultante entre gueto e prisão impõe a marginalidade 
socioeconômica e a mancha simbólica de um subproletariado negro urbano. (WACQUANT, 2002, p. 29, tradução nossa).

Segundo Wacquant (2001), uma análise mais completa revela que esse crescente uso da prisão para reforçar a divisão de castas na sociedade americana faz parte de uma "ampliação" do setor penal do Estado, que juntamente com a drástica redução de seu setor de bem-estar social, visa reforçar um regime de trabalho assalariado flexível e casual como uma norma de cidadania para segmentos não qualificados da classe trabalhadora pós-industrial. Esse emergente governo de pobreza envolve um mercado de trabalho desregulado e um severo sistema punitivo. Há um sistema de instituições de gênero que monitoram, treinam e neutralizam populações supérfluas para o novo regime econômico e racial: os homens são manuseados por sua ala penal, enquanto as mulheres e as crianças são gerenciadas por um sistema renovado de assistência social e trabalho projetado para reforçar o emprego casual e precário.

Jonathan Simon, professor de Sociologia do Direito em Berkeley, define com segurança a nova ordem do Estado penal americano contemporâneo:

Na nova ordem do Estado penal, impera a lógica do Estado mínimo, da proteção mínima contra riscos econômicos e sociais, da responsabilização individual. $\mathrm{O}$ direito penal é aquele que, diante de um problema social complexo, que resulta da interação de muitos fatores muitas vezes históricos ou sistêmicos, produz sempre uma resposta baseada na responsabilidade individual. (SIMON, 2007, p. 53, tradução nossa).

\section{Encarceramento em massa da população negra e o gueto como prisão étnico-racial}

A lei sobre a responsabilidade individual do trabalho, rubricada por Clinton em 1996, consiste em abolir o direito a assistência para as crianças mais desfavorecidas e substituí-lo pela obrigatoriedade do salariado desqualificado e subpago para seus pais. Afeta apenas um setor menor dos gastos sociais voltados para as famílias pobres. O objetivo declarado desta lei é reabsorver não a pobreza, mas a pretensa dependência das famílias assistidas em relação aos programas sociais. Estas medidas são populares junto ao eleitorado das classes médias brancas, pois a ideia fixa continua a ser que a assistência aos pobres só serve para manter na ociosidade e no vício os habitantes do gueto. No papel, a reforma visa fazer as pessoas passarem da assistência ao emprego, porém não há previsão de nenhum orçamento para formação profissional ou criação de postos de trabalho. 
A reforma revoga o direto à assistência de que as crianças desfrutam e instaura uma duração máxima acumulada de cinco anos de assistência por cada vida. Os estados e condados têm toda a liberdade de ação para impor condições de atribuições dos auxílios mais restritivas do que as enunciadas pela lei federal. Esta lei institui um sistema de prêmios e penalidades financeiras encorajando os estados a eliminar por todos os meios os assistidos. Os orçamentos da assistência passam a ser determinados atualmente não em função das necessidades das populações, mas por dotações fixas. A nova legislação exclui do registro das verbas várias categorias sociais, a exemplo dos imigrantes legais chegados a menos de 10 anos e crianças pobres sofrendo de deficiência física.

\begin{abstract}
Assim, o crescimento hipertrófico da prisão é um componente de uma reestruturação mais abrangente do Estado americano para atender às exigências do neoliberalismo. Mas a raça desempenha um papel especial neste sistema emergente. Os Estados Unidos ultrapassam largamente todas as nações avançadas na tendência internacional para a penalização da insegurança social. E assim como o desmantelamento dos programas de assistência social foi acelerado por uma confusão cultural e política de escuridão e imerecimento, também o "grande confinamento" dos rejeitos da sociedade de mercado, os pobres, os doentes mentais, os sem-abrigo, os desempregados e inúteis, podem ser pintados como uma "repressão" bemvinda sobre eles, aqueles criminosos de pele escura de um grupo de parias ainda considerados estranhos ao corpo nacional. O sistema prisional reflete e reforça a divisão racial da sociedade americana e desempenha um papel fundamental no modelo de um estado pós-keynesiano. (WACQUANT, 2002, p. 25, tradução nossa).
\end{abstract}

Wacquant relembra às mudanças ocorridas no sistema penitenciário americano após a derrocada do estado de bem estar social. Essa brusca mudança no acesso a benefícios previdenciários, que passou a ser mais difícil e criterioso, além de modificações na legislação, que somados ao endurecimento penal passaram a ter forte impacto no perfil do encarcerado americano, que nada mais é do que um órfão do sistema de bem estar social e que se vê em condição de vulnerabilidade social e mais suscetível a prática de crimes que o levam diretamente ao cárcere. A prisão é a nova instituição peculiar dos Estados Unidos, e na prática é um substituto do gueto. Uma instituição peculiar visa confinar e controlar os afroamericanos. A escravidão, o sistema Jim Crow (sistema legal de segregação), o gueto e a prisão são exemplos de instituições peculiares. Segundo Wacquant (2009), o gueto é um modo de prisão-social, enquanto a prisão funciona à maneira de um gueto judiciário.

O gueto é um dispositivo socioespacial que permite a um grupo dominante explorar um grupo dominado. O gueto é uma relação étnico-racial de controle e de fechamento 
composta de quatro elementos: estigma, coação, confinamento territorial, e segregação institucional. Gueto como prisão étnico-racial: põe na gaiola um grupo desprovido de honra e amputa gravemente as chances de vida de seus membros a fim de assegurar ao grupo dominante monopolização dos bens e das oportunidades materiais

O pensamento que corrobora neste raciocínio é o de Wacquant (2009), que afirma que não é a multiplicação de incivilizados que faz um bairro se tornar violento, mas é a decadência econômica e a segregação que, ao minar as possibilidades de vida, alimentam possíveis distúrbios. Desta forma o negro e pobre acaba abandonado à própria sorte, ficando preso, muitas vezes injustamente, ou até mesmo cumprindo uma pena maior do que o crime supostamente cometido.

O encarceramento também tem um grande efeito no índice de desemprego. Se por um lado mascara este índice, retirando à força milhões de pessoas da "população em busca de um emprego", por outro só contribui para o seu crescimento. Como menciona Wacquant (2002), um efeito do encarceramento é o de acelerar o desenvolvimento do trabalho assalariado de miséria e da economia informal, produzindo incessantemente um grande contingente de mão de obra submissa disponível: os antigos detentos não podem pretender senão os empregos degradados e degradantes, em razão de seu status judicial. Isso é agravado quando pensamos, por exemplo, que em alguns estados nos Estados Unidos se tem uma base de fichas criminais que muitas vezes é disponível a indivíduos e empresas, o que dificulta ainda mais a reinserção de ex-detentos na sociedade e no mercado de trabalho. Mantêm-se assim um círculo vicioso: a miséria alimenta o sistema carcerário, que por sua vez produz mais miséria.

A gestão da miséria nos Estados Unidos se confunde muitas vezes com o controle de negros e latinos, e se expressa no crescente encarceramento de parte dessa população. Os Estados Unidos definem o cárcere como opção para governar os desafortunados num país extremamente ligado ao consumismo. Expandindo gastos públicos para confirmar sua administração penal, gastando excessivamente em penitenciarias e prisões, prendendo cada vez mais, midiatizando ações de segurança pública de forma a demonstrar aos eleitores descontentes com o aumento da criminalidade que o Estado faz sua parte em prender vagabundos e desocupados (WACQUANT, 2009).

[...] o corte dos programas sociais retoma o áspero caminho rumo à ascensão da miséria e da violência ao hipertrofiar o direito penal e sua força sancionadora, buscando os locais de guetos e onde se encontrarem as famílias mais pobres, que passam a ser em maior número tendo em vista a redução dos programas sociais do Estado. A destruição do Estado social e a hipertrofia súbita do Estado penal são dois desenvolvimentos concomitantes 
e complementares, ou seja, o estabelecimento de um governo da miséria. (WACQUANT, 2009, p. 85).

Devido a diversas críticas à política carcerária americana, manifestações em redes sociais e a atuação de grupos ativistas a exemplo do Black Lives Matter, que pressionam a opinião pública e autoridades policiais, os Estados Unidos vivenciam atualmente um pequeno decréscimo em sua taxa de encarceramento, embora os números continuem alarmantes.

Figura 01: Evolução da População Prisional Americana, 1925 a 2015

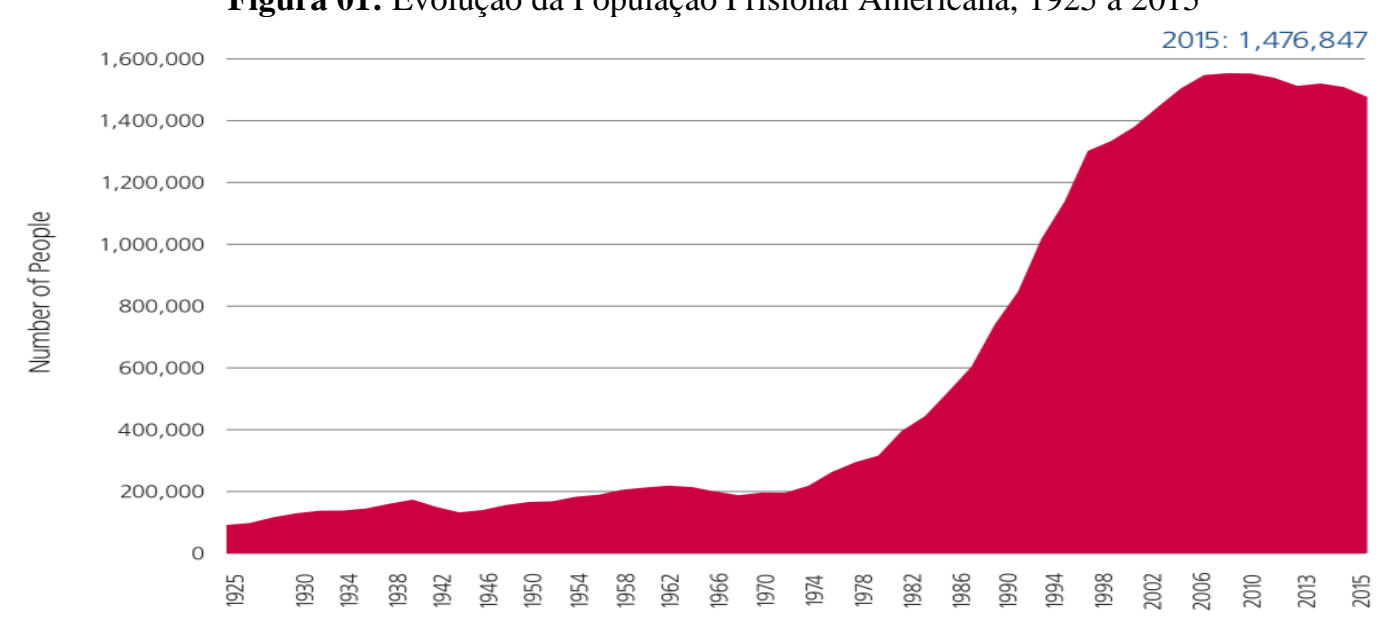

Fonte: Bureou of Justice Statistics Prisioners Series.

O Brasil ocupa o terceiro lugar no ranking de países que mais encarceram no mundo, seguindo os passos dos Estados Unidos e levantando um forte alerta às autoridades quanto a este avanço. Segundo Waiselfisz (2016), o perfil da população selecionada pelo sistema prisional brasileiro é bem específico e semelhante ao americano, uma vez que as maiores vítimas deste sistema são os jovens ( $74 \%$ dos presos no país têm menos de 35 anos), negros (67\%) e de baixa escolaridade (quase $70 \%$ dos presos não concluíram o ensino fundamental).

Outra preocupação relevante, é que os índices de encarceramento brasileiro seguem em ritmo de crescimento contínuo desde 1995. O levantamento de dados mais recente revela que o número de vagas no sistema prisional diminuiu, na contramão da população carcerária, gerando superlotação. Além de possuir a maior taxa de presos sem julgamento, cerca de $40 \%$ no ano de 2016, segundo fontes do ministério da justiça.

Porém ao invés de buscar uma diminuição de sua população carcerária, rediscutindo leis e aumentando as audiências de custódia, o governo brasileiro opta por manter e ampliar as verbas para a construção de presídios, aumentando o encarceramento em massa de pobres, negros e jovens (WAISELFISZ, 2016). 


\section{Considerações finais}

A triste realidade estadunidense de discriminação racial, criminalização da população pobre e aprisionamento dos negros se repete Brasil, os guetos e hiperguetos americanos equivalem as nossas Cohabs e favelas. O Estado tende a cada vez mais monopolizar seu caráter social em favor dos privilegiados, que são as empresas, possuidoras de garantias e apoio inúmeros, bem como às classes superiores. Contudo, isolou as classes inferiores da maneira a transformá-la na mão de obra barata oriunda dos guetos e das pequenas comunidades carentes. Deste modo, a reforma do sistema social serve para vigiar e punir os grupos que se ajustam dominados por uma classe que se encontra no topo da pirâmide, mas que somente sobrevive graças ao esforço e ao sustento daqueles que estão na margem desta construção. Esse mergulho na obra de Loic Wacquant nos dá subsidio para compreensão das altas taxas de encarceramento estadunidense e esclarece a verdadeira causa do problema, que não é simplesmente o aumenta da criminalidade e sim a população pobre, carente e excluída como alvo para punição e aprisionamento, executando uma verdadeira "limpeza social" retirando essa classe desprivilegiada das cidades e a aprisionando. Este estudo nos ajuda a compreender melhor o crescimento das taxas de encarceramento no Brasil, que também guarda semelhanças com o cenário estadunidense, quando o perfil do prisioneiro brasileiro também é o negro, jovem, morador de favelas, com baixa escolaridade e excluído dos programas sociais de benefício assistencial.

\section{REFERÊNCIAS}

SIMON, J. Governing Through Crime: How the War on Crime Transformed American Democracy and Created a Culture of Fear. New York: Oxford University Press, 2007.

WACQUANT, L. "Deadly Symbiosis: When Ghetto and Prison Meet and Merge."

Punishment and Society, v. 3, n. 1, p. 95-134, 2001.

WACQUANT, L. “Deadly Symbiosis”. Boston Review, v. 27, n. 2, p. 23-31, 2002.

WACQUANT, L. Punir os pobres: a nova gestão da miséria nos Estados Unidos. Rio de Janeiro: Revan, 2009.

WAISELFISZ, J. J. Mapa da Violência 2016: Mortes Matadas por Armas de Fogo. Rio de Janeiro, FLACSO/CEBELA, 2016. 


\section{Como referenciar este artigo}

DANIN, Renata Almeida. Loic Wacquant: encarceramento em massa como política social na contemporaneidade. Rev. Sem Aspas, Araraquara, v. 6, n. 2, p. 125-133, jul./dez., 2017. eISSN: $2358-4238$.

Submetido em: 04/10/2017

Aprovado em final em: 03/03/2018 